\title{
Ameliyat öncesi klinik değerlendirme, radyolojik planlama ve düzeltmenin hesaplanması
}

\author{
Preoperative clinical evaluation, radiological planning and \\ estimating the amount of correction
}

\author{
Yasin Güler ${ }^{1}$, Sevan Sıvacıoğlu², Mehmet Erdil²
}

${ }^{1}$ Medipol Üniversitesi, Ortopedi ve Travmatoloji Anabilim Dalı, İstanbul
${ }^{2}$ Acıbadem Maslak Hastanesi, Ortopedi ve Travmatoloji Bölümü, İstanbul

Diz çevresi osteotomileri gonartroz tedavisinde özellikle de mekanik aksın bozuk olduğu durumlarda artroplasti cerrahisi öncesi yapılan tedavi yöntemidir. Başarılı sonuçlar alınmasında doğru hasta seçimi ve dikkatli ameliyat öncesi değerlendirme çok önem taşır. Bu derlemede, diz çevresi osteotomi hastalarında dikkat edilmesi gereken klinik durumlar, doğru değerlendirme için yapılması gereken klinik muayene ile düzeltme miktarının ve yönteminin belirlenmesi için gereken radyolojik değerlendirme anlatılmıştır.

Anahtar sözcülkler: diz; osteotomi; ölçüm

\section{KLINIKK VE RADYOLOJiK DEĞERLENDIRME}

\section{Klinik Muayene}

Ameliyat öncesi fizik muayene ve anamnez ile değerlendirme, diz eklemi çevresi osteotomisi planlamasının ve yapılacak hazırlığın temelini oluşturur. Hastanın aktivite beklentisi, geçirilmiş cerrahi, travma hikâyesi ve profesyonel olarak uğraşılan spor aktivitesi gibi durumların özellikle sorgulanması gerekir. Takvim yaşından ziyade biyolojik yaşa göre endikasyon belirlemek tercih edilir. Romatoid artrit varlığı, ileri yaş (60-70 yaş ve üstü), aşırı kilolu olma ve sigara kullanımı gibi osteotomi hattında kaynama gecikmesine sebep olabilecek faktörler osteotomi için kontrendikasyonlardan olup bu durumlarda diz artroplastisi daha iyi bir seçenek olabilir. ${ }^{[1,2]}$

Sistemik veya lokal enfeksiyon varlığı ekarte edilmeli; alt ekstremite cilt, yumuşak doku ve nörovasküler durumu muayene edilmelidir. Diz eklem hareketlerinde en
Osteotomies around the knee are pre-arthroplasty treatment options for gonarthrosis with malaligned knees. Meticulous pre-operative evaluation and patient selection are important factors for a successful surgery. In this review, clinical tips for the knee osteotomy patients, physical examination for accurate evaluation, and radiological evaluation for determining the correction amount and surgical technic were described.

Key words: knee; osteotomy; measurement

azından $120^{\circ}$ fleksiyon olması ve ekstansiyon kısıtlılığının $20^{\circ}$ 'yi aşmaması gerekmektedir. Bacak uzunluğu, anteroposterior ve mediolateral ligament stabilitesi, supin ve tam yük verirken ayrı ayrı alt ekstremite dizilimi değerlendirilmelidir. Medial kompartmandaki sorun varus stresiyle şiddetlenirken valgus stresi ağrıyı azaltır.

Unikompartmantal artriti, kompleks deformiteleri, bacakta dizilim kusuru ve dizde bağ instabilitesi olan hastalara diz çevresi osteotomisi yapılabilir.

\section{Unikompartmantal osteoartrit}

Yük taşıma esnasında ortaya çıkan ağrı nedeniyle başvuran unikompartmantal artriti olan hastaların şikayetlerinin direkt medial ya da lateral kompartmanla ilişkilendirilebilmesi doğru endikasyon açısından önemlidir. Eklem kıkırdağında belirgin dejenerasyon ve patellofemoral ağrı göreceli kontrendikasyon iken aşırı ağrı ifade eden hastaların osteotomiden fayda görmemeleri muhtemeldir.

- Illetişim adresi: Prof. Dr. Mehmet Erdil, Acıbadem Maslak Hastanesi, Ortopedi ve Travmatoloji Bölümü, İstanbul Tel: 0532 - 4249732 e-posta: mehmeterdil@hotmail.com

- Geliș tarihi: 20 Ocak 2020 Kabul tarihi: 17 Mart 2020 


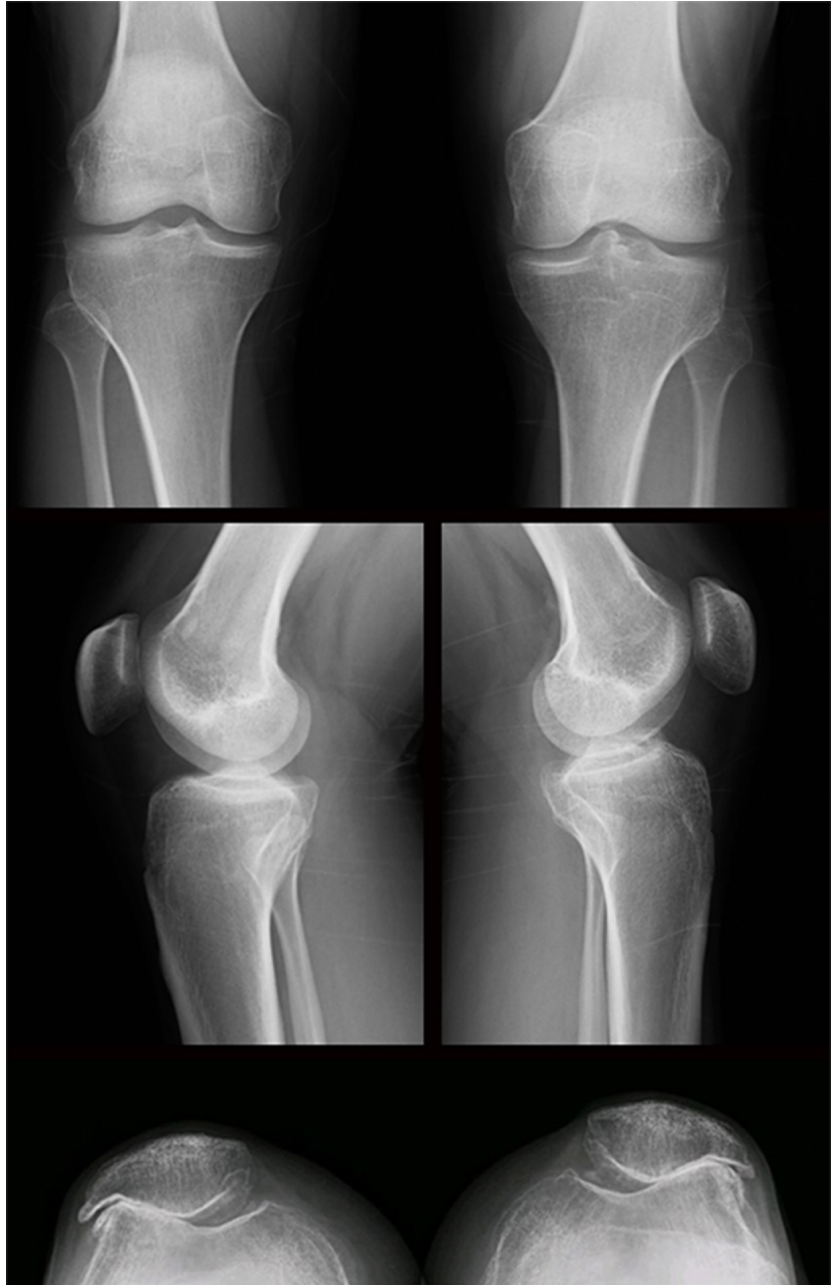

Şekil 1. Diz ekleminin tam yük vererek çekilen ön-arka (AP) (üstte), lateral (ortada) ve patella tanjansiyel (altta) radyografileri ile değerlendirme yapılmalıdır.

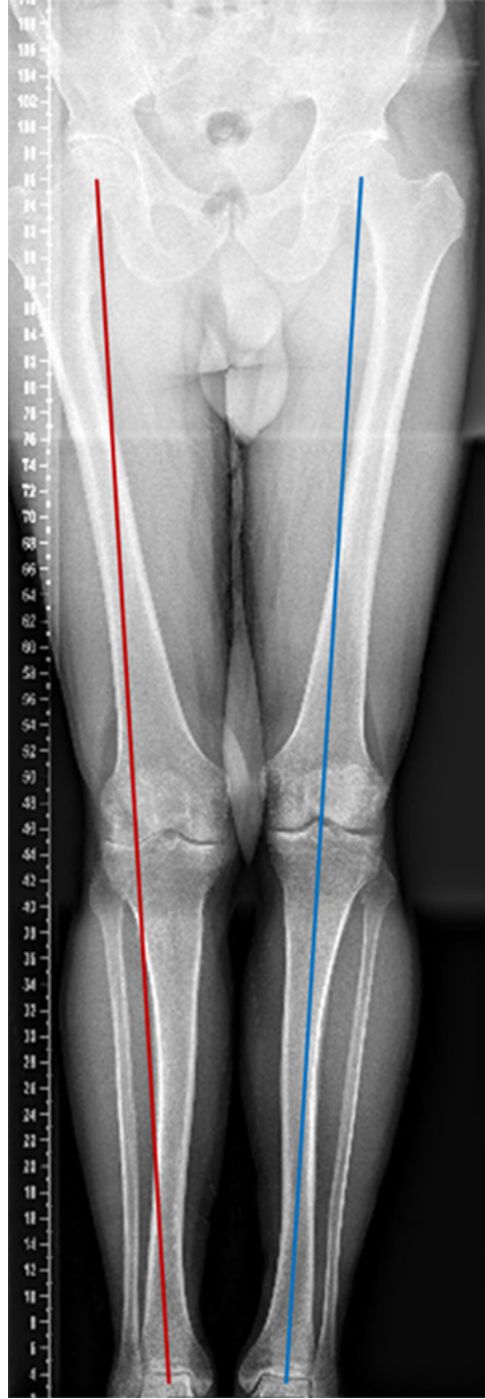

Şekil 2. Mikulicz çizgisi, mekanik aks; femur başının orta noktasından ayak bileğinin orta noktasına uzanan çizgidir.

\section{Diz instabilitesi ve dizilim bozukluğu}

Bağ instabilitesi ve bacakta varus dizilim bozukluğu olan hastalar da diz çevresi osteotomisiyle tedavi edilebilir. Medial eklem aralığında kıkırdak dejenerasyonu da olan bu hastalar osteoartroz hastalarına göre ağrıdan ziyade instabilite ve dizde boşalma hissi şikâyetlerine sahiptirler. Bu hastalarda osteotomiye ek olarak bağ rekonstrüksiyonu veya valgizasyon-fleksiyon/valgizasyon-ekstansiyon iki planlı osteotomileri uygulanabilir.

\section{Kompleks deformiteler}

Konjenital deformiteler, malunion ve nörolojik hastalıklara bağlı ortaya çıkabilen kompleks deformitelerde tam bir muayene sonrasında deformite seviyesinin lokalizasyonu ve deformitenin karakteri doğru olarak tespit edilmelidir. Frontal planda varus/valgus dizilim bozukluğuna sagittal planda fleksiyon/ekstansiyon dizilim bozukluğunun eşlik edebildiği birden fazla seviyede aks sapmaları olabilir. Ayrıca femur ve tibianın torsiyonel deformitelerinin de klinik ve radyolojik olarak iyi irdelenmesi gerekir.

\section{Radyolojik Değerlendirmeler \\ Radyografik inceleme}

Diz ekleminin ön-arka (AP), yan, patella tanjansiyel ve tam yük vererek çekilen röntgenografileriyle ameliyat öncesi anatomik ve mekanik aks değerlendirmesi yapılmalıdır (Şekil 1 ve Şekil 2). Bacak uzunluk grafisi tam yük verilirken AP pozisyonda ışın horizontal 
düzlemde ekleme odaklanarak çekilmeli, rotasyonel bozukluğu önlemek için patella femoral kondilin tam ortasına gelecek şekilde konumlandırılmalıdır. ${ }^{[3]}$ Rosenberg grafisi ile etkilenen kompartmandaki eklem daralması ve deformitenin seviyesi konusunda fikir edinilebilir. Görüntülenmesi şart olmayan bu grafi dizler $45^{\circ}$ fleksiyondayken arkadan öne tibianın arkaya eğimine paralel olarak çekilir. ${ }^{[4]}$ Kollateral bağ stabilitesinin değerlendirilmesinde varus ve valgus stres grafileri yardımcı olabilir. Ameliyat öncesi lateral bağ yetmezliğinin tespit edildiği osteoartrozik varus dizlerde aşırı düzeltmeden kaçınılmalıdır.

\section{Manyetik Rezonans Görüntüleme (MRG)}

Diz çevresi osteotomileri öncesinde manyetik rezonans görüntüleme meniskal ve bağ lezyonların ortaya konulmasını sağlar. Etkilenen kompartmanın durumunu değerlendirmede her ne kadar kullanılabilse de neredeyse tüm vakalardan önce kıkırdak değerlendirmesi açısından tanısal artroskopi yapılması tercih edildiği için bu inceleme şart değildir.

\section{Bilgisayarlı Tomografi (BT)}

Alt ekstremitenin torsiyonel dizilim bozukluğunun olduğu hastalarda altın standart olan BT, travma sonrası oluşan defektlerin ve kemik lezyonlarının osteotomi öncesinde ayrıntılı değerlendirilmesinde kullanılabilir.

\section{Diz Çevresi Osteotomilerinin Temel Prensipleri}

Planlama için normal anatomik alt ekstremite anatomisinin, fizyolojik açılarının ve akslarının anlaşııması çok önemlidir. Alt ekstremitenin yük-binme çizgisi (Mikulicz çizgisi, mekanik aks) femur başının orta noktasından ayak bileğinin orta noktasına uzanan çizgidir (Şekil 2). Bu çizginin diz eklemini kestiği nokta ile dizin orta noktası arasındaki mesafe mekanik aks kaymasını ya da deviasyonu belirler. Fizyolojik olarak diz ekleminin orta noktası ya da hafif medialinden geçer. Planlama yaparken tüm alt ekstremiteyi içeren ayakta basarken çekilen röntgenografiler, deformitenin tipi-yeri ve bağların durumu belirleme de değerlidir.

\section{Osteotomi seviyesi}

Farklı avantaj ve dezavantajları olan çok sayıda planlama metodunda amaç ilk olarak deformitenin tipi ve yerinin belirlenmesidir. Seçim konusunda en iyi yönlendirici cerrahın tecrübesi ve kendini güvende hissettiği metottur.

Osteotominin deformitenin apeksine uygulanması daha kolay deformite düzeltme imkânı sunarken osteotominin metafizyel bölgeden yapılması kemik iyileşmesi açısından daha avantajıdır.
Açık kama osteotomileri kapalı kama osteotomilerine göre daha kolay ve doğru uygulanabilirdir. Ameliyat sırasında ayırıcı aletler kullanarak açısal ince ayarlamalar yapılabilmesi mümkündür. Sabit açılı implantların kullanılması durumunda kemik grefti kullanımına gerek kalmayabilir. ${ }^{[5,6]}$

Varus osteoartritinde kapalı kama osteotomisi uzun dönem sonuçları açısından iyi-mükemmel olarak ifade edilen klasik bir tedavidir. ${ }^{[7-9]}$ Ancak proksimal fibula osteotomisi gerektirmesi nedeniyle postoperatif peroneal sinir hasarı riski mevcuttur. ${ }^{10-12]}$

\section{Düzeltme miktarı}

Dizilimi fizyolojik olan dizde yük dağılımı medial kompartmanda $\% 60$ ve lateral kompartmanda $\% 40$ oranında olup eşit değildir. ${ }^{[13]}$ Dolayısıyla medial eklem artriti olan hastada fizyolojik dizilimin sağlanması yeterli olmayacaktır ve bunun yerine yükü laterale kaydıracak bir aşırı düzeltme önerilmektedir. Düzeltilmiş aks Fujisawa skalasında medial eklem kıkırdağının kaybı oranında lateral kompartman üzerindeki skalanın \%10 ile \%35 arasında tanımlanmış olup eklem kıkırdağının $2 / 3$ nün sağlam olduğu durumlarda $\% 10-15$, eklem kıkırdağının $1 / 3$ nün sağlam olduğu durumlarda \%20-25, eklem kıkırdağının kalmadığı durumlarda ise \%30-35 oranında aksın lateralde aşırı düzeltilmesi önerilmiştir (Şekil 3). ${ }^{[14]}$

\section{Yüksel tibial osteotomi için ayrıntılı planlama algoritması}

Hafiften orta dereceye kadar osteoartriti olan semptomatik varuslu genç, aktif hastalarda tibianın proksimal valgizasyon osteotomisi tercih edilen tedavi şekillerinden biridir. Varus dizilimi olan hastaların diz mekaniği düzeltilmedikçe medial kompartman osteoartriti açısından yatkınlıkları olduğu genel kabuldür. ${ }^{[15-17]}$ Yetersiz düzeltme ve aşırı düzeltme gibi prosedürün erken başarısızlık nedenlerinden kaçınmak için ameliyat öncesi planlama çok önemlidir. ${ }^{[18,19]}$

\section{Radyografik tetkik}

Yüksek tibial osteotomi (YTO) için operasyon öncesinde planlama yapmak açışından diz artritinin derecesi ve alt ekstremite diziliminin değerlendirilebileceği tam ekstansiyonda iki taraflı yük vererek $\mathrm{AP}, 45^{\circ}$ fleksiyonda (PA) tünel (Rosenberg) grafileri çektirilir. ${ }^{[4]}$ Görüntüleme, hasta her iki alt ekstremiteye yük verirken dizin doğru rotasyonunda diz ve ayak bileği eklemlerini içerecek şekilde uzun bacak AP grafisiyle elde edilir. Planlama yapılan dizin lateral ve silüet görüntüleri de alınır.

Kalça ve ayak bileğinin aynı anda görüntülenemediği durumlarda mümkün olduğunca uzun olacak şekilde distal femur ve proksimal tibia görüntülenerek 


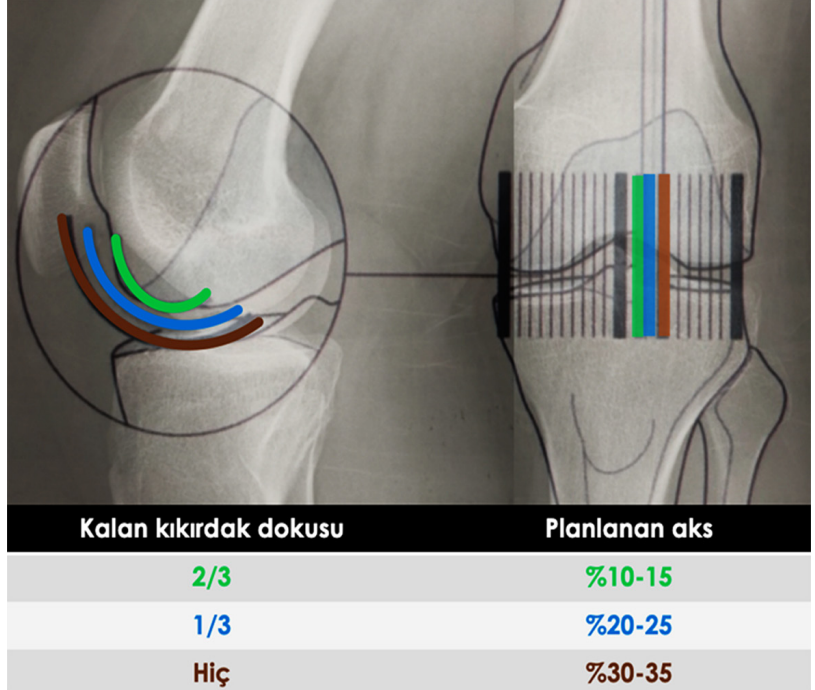

Şekil 3. Fujisawa yaptığı çalışmada eklem kıkırdak dokusunun durumuna göre düzeltme miktarını belirlemiştir. ${ }^{[14]}$

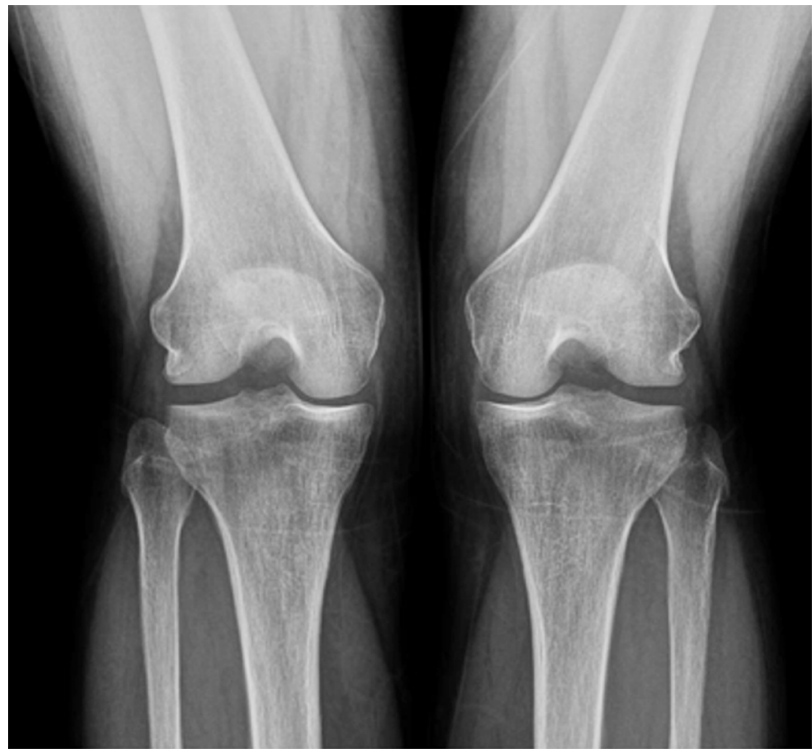

Şekil 4. Rosenberg grafisi ile artrozun diz eklemindeki yayılımı saptanmalıdır.

anatomik eksenler kullanılmasıyla doğru ölçüm yapma hedeflenir. Uygun rotasyon amacıyla patella her iki kondilin ortasına merkezlenecek şekilde konumlandırılır. Ekstansiyon kısıtlılığı olması durumunda doğru planlama yapılabilmesi amacıyla tibia ve femurun tek tek görüntülenip değerlendirilmesi gerekir. Karşılaştırmalı Rosenberg grafisi üzerinde yapılan medial eklem açılığı değerlendirmesiyle yumuşak doku gevşekliği tespit edilir (Şekil 4). ${ }^{[4]}$
Dizin varus açılanması femorotibial geometrik dizilim, kemik-kıkırdak (osteokartilajinöz) kompleks ve menisküsün zamanla aşınmasına bağlı olarak medial eklem aralığının daralması, gevşek lateral yumuşak doku ve bağlar nedeniyle lateral eklem aralığının ayrılması sebepleriyle ortaya çıkar.

Varus deformitelerinin ameliyat öncesi planlamasında ve önerilen optimum düzeltme miktarını hesaplamada, mekanik ve anatomik femorotibial açıları değerlendirmek için, ağılık taşıma hattının kullanıldığı bir çok metod tespit edilmiştir. Fujisawa optimum zonu lateral tibia platosunun \%30-40 genişliği olarak tanımlamış ve YTO'dan sonra yük binme çizgisinin buradan geçmesi durumunda kıkırdak hasarının (ülserasyonunun) artmadığını tespit etmiştir. ${ }^{[14]}$ Frontal düzlemde ameliyat sonrası optimum dizilimin tibial genişliğin lateral \%62-66'ından geçen bir yük taşıma çizgisi (YTÇ), $3^{\circ}-5^{\circ}$ lik valguslu mekanik eksen ya da $8^{\circ}{ }_{-}$ $10^{\circ}$ 'lik valguslu bir anatomik eksen ile elde edilebilir.

\section{Frontal düzlemde operasyon öncesi planlama}

Frontal/koronal düzlem düzeltilmesinin belirlenmesinde yük binme çizgisinin (YBÇ) önerildiği Miniaci'nin yönteminde birinci hat operasyon sonrası için planlanan, femur başı merkezinden başlayıp tibianın \%60-70'inden geçerek ayak bileği merkezine uzanan YBÇ'yi temsil eder. Osteotomi menteşe noktasını $(\mathrm{H})$ ayak bileği merkezine bağlayan ise ikinci hattır. Osteotomi menteşe noktası $(\mathrm{H})$ merkez ve ikinci hat uzunluğu yarıçap kabul edilerek birinci hat ile kesişim noktasına kadar bir açı çizilir. Osteotomi menteşe noktası ile birinci hat arkını birleştiren, üçüncü hat olarak kabul edilir. Üçüncü hatla ikinci hat arasında oluşan ' $\mathrm{X}$ ' açısı planlanan düzeltme açısı olarak kabul edilir. ${ }^{[20]}$

Osteotomi menteşe noktası açık kama osteotomisinde lateral proksimal metafiz üzerinde, lateral platonun subkondral skleroz bölgesinin yaklaşık $15 \mathrm{~mm}$ inferiorunda, tibiofibular eklemin proksimal sınır düzeyinde bulunur. Kapalı kamada eklem hattının yaklaşık $2,5 \mathrm{~cm}$ inferiorunda medial proksimal tibia metafizinde osteotomi menteşe noktası belirlenir. Menteşe noktası tepe noktası olacak şekilde düzeltme açısı (x) kullanılarak proksimal tibiada üçgen oluşturulur. Açık kama osteotomisinde medial kortekse denk gelen taban osteotominin açıklığına denk gelirken; kapalı kamada üçgenin tabanı rezeke edilecek kamanın yüksekliğine karşılık gelir (Şekil 5).

Dugdale ve ark. da YBÇ'nin kullanıldığı iki farklı ameliyat öncesi planlama yöntemi belirtmişlerdir .[21] Birinci yöntemde femur başı merkezinden başlayan birinci hat tibianın \%62,5 genişliğinden geçer. Tibiotalar eklemin merkezinden bu \%62,5'lik hatta uzanan çizgi ikinci hattır. Bu iki hattın arasında kalan açı (x) 


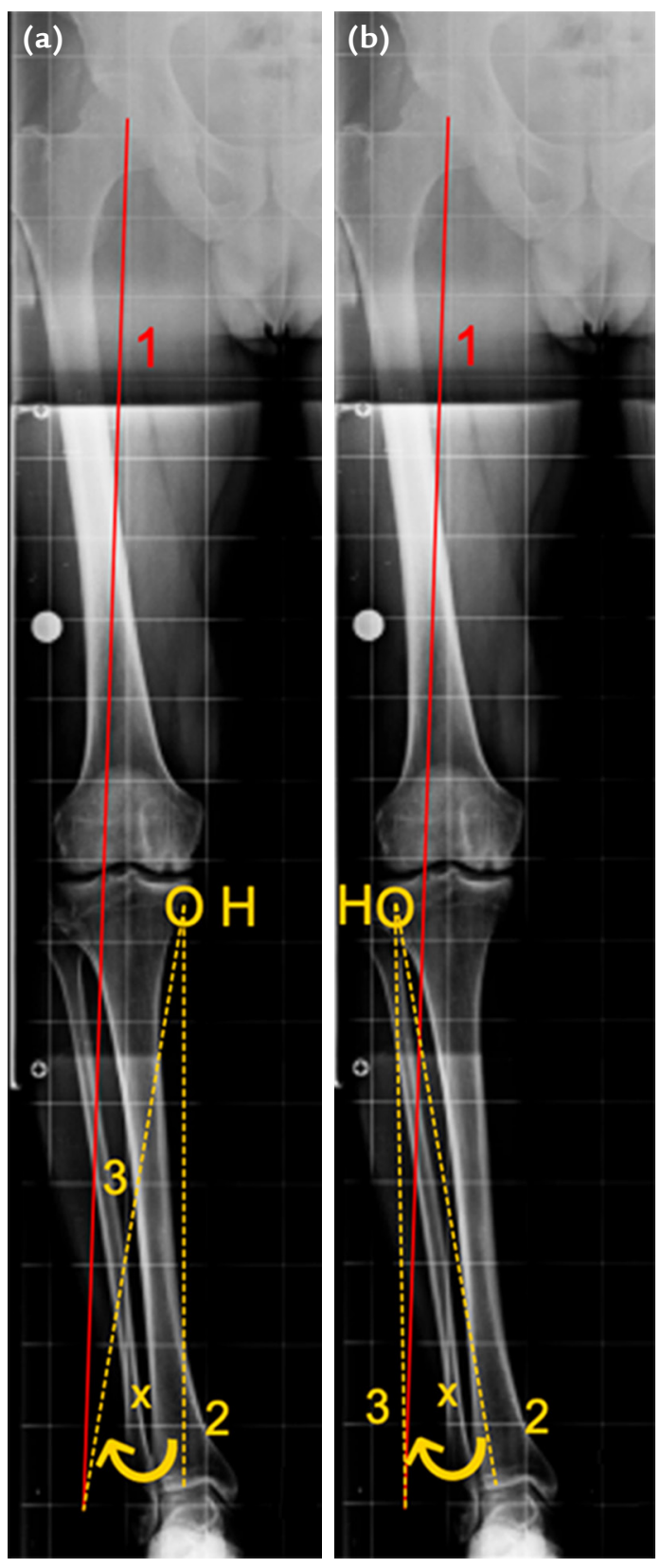

Şekil 5. a, b.

Ekstansiyonda çekilen AP ortoröntgenografiler üzerinde Miniaci'nin tarif ettiği yönteme göre osteotomi planlaması (1: Hedeflenen mekanik aksa göre femur başından tibial plato$\mathrm{da}$ planlanan ağırlık merkezine çizilen çizginin ayak bileği seviyesine kadar uzatılması, 2: Menteşe noktasından ayak bileği orta hattına çizilen mekanik aks, 3: Menteşe noktasından ayak bileği seviyesinde planlanan mekanik aks çizgisine çizilen çizgi, x: düzeltme açısı, H: menteşe noktası). Kapalı kama yüksek tibia osteotomisi planlanması (a). Açık kama yükssek tibia osteotomisi planlanması (b).

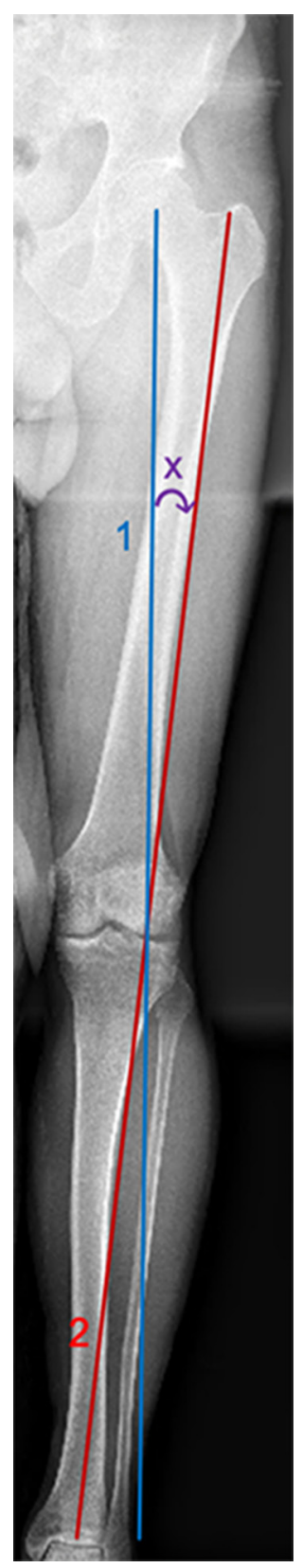

Şekil 6.

Ekstansiyonda çekilen AP ortoröntgenografiler üzerinde Dugdale ve ark.'nın tarif ettiği yönteme göre osteotomi planlamasi; (1: Femur başı merkezinden başlayan tibianın \%62,5 genişliğinden geçen hat, 2: Tibiotalar eklemin merkezinden bu \%62,5'lik hatta uzanan hat, x: Bu iki hattın arasında kalan açı düzeltme açısı). düzeltme açısıdır (Şekil 6). Diğer planlama yönteminde ise femur başının merkezinden tibianın \%62,5'luk bölgesine bir hat çizilir. Osteotomi bölgesi üzerinden şablon röntgen kesilir ve yük binme çizgisi \%62,5'lik bu hattan geçene kadar distal tibia döndürülür.

Coventry ${ }^{[22]}$ planlamasını ameliyat öncesi ve planlanan anatomik eksenler arasındaki açısal farkın rezeke edilecek açısal kama olacağı fikrine dayandırır. Yalnızca kısa AP görünümü mevcut olduğunda yararlı olan bu yöntemde ameliyat öncesi $4^{\circ}$ varusluk ameliyat öncesi (preop) anatomik eksen, ameliyat sonrası (postop) anatomik eksen şeklinde düzeltilecek ise aşağıdaki denklem kullanılabilir. Planlama da mekanik eksen de kullanılabilir. ${ }^{[23]}$

$$
\begin{aligned}
& X=(A A \text { post } O P)-(A A \text { pre } O P) \\
& X=8-(-4)=12
\end{aligned}
$$




\section{KAYNAKLAR}

1. Job-Deslandre C, Languepin A, Benvenuto $M$, et al. Tibial valgisation osteotomy in gonarthrosis with or without chondrocalsinosis. Results after 5 years. Rev Rheum Mal Osteoarttk 1991;58(7):491-6.

2. Coventry MB. Proximal tibial varus osteotomy for osteoarthritis of the lateral compartment of the knee. J Bone Joint Surg Am 1987;69(1):32-8. Crossref

3. Jakob RP, Jacobi M. Closing wedge osteotomy of the tibial head in treatment of single compartment arthrosis. Orthopade 2004;33(2):143-52. Crossref

4. Rosenberg TD, Paulos LE, Parker RD, Coward DB, Scott $\mathrm{SM}$. The forty-five degree posteroanterior flexion weightbearing radiograph of the knee. J Bone Joint Surg Am 1988;70(10):1479-83. Crossref

5. Staubli AE, De Simoni C, Babst R, Lobenhoffer P. TomoFix: a new LCP -concept for open wedge osteotomy of the medial proximal tibia- early results in 92 cases. Injury 2003;34(Suppl 2):B55-62. Crossref

6. Lobenhoffer P, Agneskirchner JD. Improvements in surgical technique of valgus high tibial osteotomy. Knee Surg Sports Traumatol Arthrosc 2003;11(3):132-8. Crossref

7. Insall JN, Joseph DM, Msika C. High tibial osteotomy for varus gonarthrosis. A long-term follow-up study. J Bone Joint Surg Am 1984;66(7):1040-8. Crossref

8. Coventry MB, Ilstrup DM, Wallrichs SL. Proximal tibial osteotomy. A critical long-term study of eighty-seven cases. J Bone Joint Surg Am 1993;75(2):196-201. Crossref

9. Aglietti P, Buzzi R, Vena LM, Baldini A, Mondaini A. High tibial valgus osteotomy for medial gonarthrosis: a 10 to 21 year study. J Knee Surg 2003;16(1):21-6.

10. Flierl S, Sabo D, Hornig K, Perlick L. Open wedge high tibial osteotomy using fractioned drill osteotomy: a surgical modification that lowers the complication rate. Knee Surg Sports Traumatol Arthrosc 1996;4(3):149-53. Crossref

11. Georgoulis AD, Makris CA, Papageorgiou CD, Moebius UG, Xenakis T, Soucacos PN. Nerve and vessel injuries during high tibial osteotomy: clinically relevant anatomic study. Knee Surg Sports Traumatol Arthrosc 1999;7(1)15-9. Crossref
12. Hofmann S, Pietsch M, van Heerwaarden R. Biomechanical principles and planning for osteotomies around the knee joint. Orthopaedische Praxis 2007;43(3):109-15.

13. Johnson F, Leitl S, Waugh $W$. The distribution of load across the knee. A comparison of static and dynamic measurements. J Bone Joint Surg Br 1980;62-B(3):346-9. Crossref

14. Fujisawa $Y$, Masuhara K, Shiomi S. The effect of high tibial osteotomy on osteoarthritis of the knee. An arthroscopic study of 54 knee joints. Orthop Clin North Am 1979;10(3):585-608.

15. Aglietti $P$, Rinonapoli E, Stringa G, Taviani A. Tibial osteotomy for the varus osteoarthritic knee. Clin Orthop Relat Res 1983;(176):239-51. Crossref

16. Coventry MB. Osteotomy of the upper portion of the tibia for degenerative arhritis of the knee. A preliminary report. J Bone Joint Surg Am 1965;47(5):984-90. Crossref

17. Tjornstrand B, Egund N, Hagstedt B, Lindstrand A. Tibial osteotomy in medial gonarthrosis. The importance of overcorrection of varus deformity. Arch Orthop Trauma Surg 1981;99(2):83-9. Crossref

18. Engel GM, Lippert FG 3rd. Valgus tibial osteotomy: avoiding the pitfalls. Clin Orthop Relat Res 1981;(160):137-43. Crossref

19. Kettelkamp DB, Wenger DR, Chao EY, Thompson C. Results of proximal tibial osteotomy. The effects of tibiofemoral angle, stancephase flexion-extansion and medial plateau force. J Bone Joint Surg Am 1976;58(7):952-60. Crossref

20. Miniaci A, Ballmer FT, Ballmer PM, Jacob RP. Proximal tibial osteotomy. A new fixation device. Clin Orthop Relat Res 1989;(246):250-9. Crossref

21. Dugdale TW, Noyes FR, Styer D. Preoperative planning for high tibial osteotomy. The effect of lateral tibiofemoral separation and tibiofemoral length. Clin Orthop Relat Res 1992;(274):248-64. Crossref

22. Coventry MB. Upper tibial osteotomy for osteoarthritis. J Bone Joint Surg Am 1985;67(7):1136-40. Crossref

23. Brown G, Amendola A. Radiographic evaluation and preoperative planning for high tibial osteotomies. Operative Techn Sports Med 2000;8:2-14. Crossref 